\title{
El cine y su condición de artisticidad: un acercamiento a la teoría fílmica de Béla Balázs
}

\author{
Santiago Martín López Delacruz \\ Universidad de la República, Uruguay \\ santiagolopezdelacruz@gmail.com \\ Artículo bajo licencia Creative Commons \\ Atribución 4.0 Internacional (CC BY 4.0) \\ ENVIADO: 2019-03-01 \\ ACEPTADO: 2019-06-17
}

\section{RESUMEN}

El presente trabajo tiene como objetivo indagar en los primeros años de la teoría fílmica, centrándose concretamente en la figura del teórico húngaro Béla Balázs. Analizando sus principales aportes desde el pensamiento cinematográfico, se propone explorar la teoría de Balázs desde sus tres principales perspectivas de estudio: el debate sobre la condición de artisticidad del fenómeno cinematográfico, la búsqueda por parte del cine de un lenguaje específico e independiente de otras disciplinas artísticas, y su papel en la sociedad occidental del siglo XX como medio de comunicación de masas.

PALABRAS CLAVES

Artisticidad, lenguaje cinematográfico, formalismo, montaje, teoría del cine.

\section{RESUMO}

O objetivo deste artigo é investigar os primeiros anos da teoria do cinema, focalizando especificamente a figura do teórico húngaro Béla Balázs. Analisando suas principais contribuições do pensamento cinematográfico, propomos explorar a teoria de Balázs a partir das suas três principais perspectivas de estudo: o debate sobre a condição da artisticidade do fenômeno cinematográfico; a busca pelo cinema de uma linguagem específica e independente de outras disciplinas artísticas; e o seu papel na sociedade ocidental do século XX como meio de comunicação de massa.

\section{PALAVRAS-CHAVE}

Artisticidade, linguagem cinematográfica, formalismo, montagem, teoria do cinema.

\section{ABSTRACT}

The present work aims to investigate in the early years of film theory, focusing specifically on the figure of the Hungarian theorist Béla Balázs. Analyzing its main contributions from the cinematographic thought, it is proposed to explore the theory of Balázs from its three main perspectives of study: the debate on the condition of artisticity of the cinematographic phenomenon; the search by the cinema of a specific language and independent of others artistic disciplines; and its role in the twentieth-century occidental society as a mean of mass communication.

\section{KEYWORDS}

Artisticity, cinematographic language, formalism, montage, film theory. 


\section{INTRODUCCIÓN}

El principal problema estético del cine, que fue inventado para la reproducción, es -paradójicamente-superar a la reproducción. Hans Richter (1951)

Desde su génesis, la actividad cinematográfica ha estado ligada a la reflexión teórica, ya sea por el debate acerca de su especificidad como medio, por su papel dentro de la historia industrial, artística y tecnológica, o por su relación, en mayor o menor medida, con otro tipo de artes.

Teniendo en cuenta que la reflexión teórica nace a la par que su propio medio, el pensamiento sobre el cine no es, en absoluto, nacido desde una única arista de contemplación. Para Stam, raramente la teoría del cine es pura, ya que suele venir acompañada de cierta dosis de crítica literaria, análisis sociales y especulación filosófica (2001:17), entre otros aportes desde diversas disciplinas de múltiples áreas de conocimiento.

Sin olvidar que los primeros años de la teoría y de la crítica cinematográfica se centraron en la definición del medio cinematográfico y su relación con otras artes, había un interés en demostrar la potencialidad artística del aparato cinematográfico. Algo que, entrados ya mediados del siglo XX, no se considera necesario puesto que el pensamiento teórico ya da por sentado la condición artística del cine (Stam, 2001:43).

Surgen, durante el primer cuarto del siglo XX, lo que se vienen a denominar proto-teorías o teorías en ciernes acerca del dispositivo cinematográfico, mediante aportes que, si bien se suscitan desde diversas perspectivas de estudio, no conforman paradigmas concretos o un conjunto homogéneo de pensamiento. Son, principalmente, primeros atisbos de reflexiones sobre el cine y su cada vez mayor capacidad de atención sobre la cultura y la sociedad.

El poeta Vachel Lindsay o el filósofo Hugo Münsterberg surgieron durante la década del diez para elaborar primogénitas reflexiones en torno al cine y su alcance, en tanto medio artístico en relación con su espectador. Lindsay expresaba que las películas podrían equipararse, según el género y el tratamiento narrativo al que se sometan, a una "escultura en movimiento", una "pintura en movimiento" o una "arquitectura en movimiento" (1916:4), teniendo siempre presente la equiparación del cine, al que consideraba "el arte de las imágenes móviles", con las demás artes visuales, y alejándose de las características básicas de reproducción, para centrarse en las maneras de representación fílmica e, incluso, tratando al cine como un nuevo tipo de lenguaje ${ }^{1}$. Münsterberg, por su parte, estudió al cine tanto desde el punto de vista psicológico (a través de los procesos cognitivos de atención, memoria e imaginación), como estético (mediante la experiencia obra-espectador clausurada para sí misma, y sin ningún fin más allá que el propio placer de la contemplación). Con ambos enfoques, expresó que el cine nace de la servil imitación del teatro y comienza lentamente a encontrar sus métodos artísticos, provocando que los aspectos característicos de muchas actitudes y sentimientos que no pueden expresarse sin las palabras surjan en la mente del espectador a través del sutil arte de la cámara (2005:96).

Para corroborar la pertinencia artística y estética del aparato cinematográfico, y en paralelo al desarrollo de las proto-teorías fílmicas, es importante mencionar el aporte que en el año 1911 surge con el Manifiesto de las siete artes, escrito por el italiano Riccioto Canudo. Teniendo en cuenta la clasificación establecida en el Renacimiento ${ }^{2}$, Canudo expone el hecho de que el cine es un arte de síntesis de todas las otras artes adyacentes, fruto del nacimiento entre la máquina y el sentimiento, cuya misión es alcanzar algo que las demás artes no han podido adquirir pero del cual posee completa

1 Lindsay propuso una idea pionera del cine como «lenguaje jeroglífico», cuya lengua serían las imágenes. Idea que, a posteriori, fue desarrollada por teóricos como Jean Mitry o Christian Metz, y cineastas como Sergei Eisenstein.

$2 \quad$ Canudo se basa en el Sistema de Bellas Artes propuesto por Charles Batteaux en 1747, que incluía como bellas artes: la pintura, la música, la poesía, la pintura y la danza. Dos años más tarde, Batteaux agregó dos artes nuevas: la arquitectura y la elocuencia (esta última actualmente desestimada dentro de la visión estético-material del arte). 
capacidad: la conversión en un arte total (1993:15-16). De esta forma, el teórico plantea el grado de superioridad del cine respecto a sus artes compañeras, cuyo laconismo permitirá la plenitud del arte en todas sus formas.

Por otro lado, Canudo expone que si bien el cine tiene una innegable relación con otras formas de trabajo artístico, pasados veinte años de su creación, también está en la búsqueda de sus propios medios de expresión:

Finalmente el «círculo en movimiento» de la estética se cierra hoy triunfalmente en esta fusión total de las artes que se llama "Cinematógrafo». Si tomamos a la elipsis como imagen perfecta de la vida, o sea, del movimiento - del movimiento de nuestra esfera achatada por los polos-, y la proyectamos sobre el plano horizontal del papel, el arte, todo el arte, aparece claramente ante nosotros (1993:17).

De esta manera, el pensamiento de principios del siglo $X X$ plantea que el cine establece una fusión de todas sus artes precedentes para erigirse como la forma más pura de arte, estableciendo nuevos parámetros dentro de la experiencia estética y fomentando nuevas formas de producción, distribución e interpretación de su material. Al respecto, es pertinente entender cómo el cine se ha convertido en un potente medio de comunicación de masas, a tal punto de plantear un debate sobre el concepto mismo del arte y de la experiencia artística sin estar exento de lo que su gran popularidad ha connotado desde su creación.

En los inicios del pensamiento acerca de la condición artística del cine, la fotografía había desplazado a la pintura "hacia arriba”, es decir, hacia las élites de las sociedades, mientras que el cine realizó un doble trabajo: por un lado desbordó con su alcance captando la atención popular, y por otro acaparó la atención en términos de puro prestigio artístico (Debray, 1992:230). De esta manera, y siguiendo el pensamiento del alemán Walter Benjamin, se comprende como la técnica reproductiva del cine desvincula lo reproducido del ámbito de la tradición (1989:2223).

La consideración del cine como arte plantea una ruptura en las propias formas de comprensión del significado de lo artístico, a raíz de dos factores primordiales: por un lado se trata de un medio nacido desde la reproducción misma, lo que implica la pérdida de un "original artístico", y por ende, de una forma de contemplación única. Y, en otro término, como nuevo arte, el cine comienza a establecer los cimientos de un nuevo lenguaje, una nueva forma de tratamiento de las materias primas de lo artístico y una nueva interpretación de la experiencia estética. El cine actúa como el agente más poderoso de la conmoción que sufre la tradición, suscitado por la estrecha relación que el mismo posee con los movimientos de masas de la época (Benjamin, 1989:22-23).

\section{LA PERSPECTIVA FORMALISTA}

Durante las primeras décadas de existencia del cine, surge la figura de Béla Balázs ${ }^{3}$, autor de origen húngaro, que también comienza a ver en el cine las razones de su marcada condición artística. Afianzado en una postura afín al formalismo, Balázs parte de la base que sugiere que el cine sirve a una función simbólica cuando simplemente reproduce la realidad, mientras que sirve a una función estética cuando, por medio de técnicas artificiales, fuerza a ver dicha realidad de una forma especial (Andrew, 1993:114).

La tradición formalista estuvo vinculada en sus inicios al estudio de la Literatura, aunque rápidamente su pensamiento exploró otros terrenos, entre ellos el cine. Figuras destacables como Viktor Shklovski, Boris Eijenbaum o Yuri Tinianov creyeron en un perfil marcadamente esteticista, explicando que la experiencia estética era un fin en sí mismo (Stam, 2001:67). Desde este punto, el arte está llamado a devolver obras con un innegable valor artístico a costa del trabajo de la forma por sobre el contenido y alejándose, a su vez, de toda connotación externa que no sea la obra en sí misma. Los formalistas se afianzaron en la idea de que el cine, como arte poético, debía tener la función esencial de saltear las percepciones cotidianas de la realidad a través del complejo trabajo de las formas (Stam, 2001:66)

Balázs, en un sentido aliciente al formalismo, expone que la materia prima de la realidad se puede transformar en muchas formas diferentes de arte. Pero la existencia única de un "contenido", que intente determinar la forma, ya no sería esa materia prima, sino una manipulación a los preceptos de la forma, la cual siempre resulta pura, puesto que nace de un trabajo creativo (Balázs, 1952:261). De esta manera, Balázs se familiariza con las posturas de las proto-teorías, que intentaban explicar las características del cine como arte con una línea de pensamiento basada exclusivamente en fines estéticos.

En sus trabajos, Balázs analiza desde tres variantes, también presentes en las prematuras discusiones sobre la artisticidad, al fenómeno cinematográfico: la relación del cine con las otras artes, la búsqueda de un lenguaje fílmico específico y autónomo, y la misión de lo cinematográfico desde su carácter estético para lograr la identificación con las masas, puesto que el nacimiento del arte fílmico no sólo se deduce a la creación de nuevas obras de arte, sino a la emergencia de las nuevas facultades humanas con las que percibir y entender este nuevo arte (1952:33).

En última instancia, y similar a lo planteado por Benjamin, la visión de Balázs apunta a la observación sobre la forma en la que los diversos aspectos de la realidad se moldean a la presencia de un lenguaje fílmico, valorándose el trabajo del artista (el realizador cinematográfico) en tanto responsable de narrativas y temas acordes a la artisticidad fílmica, y atendiendo con especial interés la influencia del cine en la comprensión e interpretación de nuevas tradiciones artísticas. 


\section{LA FUNCIÓN DEL CINE EN LA SOCIEDAD OCCIDENTAL}

En su su obra El hombre visible o El espíritu del Film, publicado originalmente en 1924, Béla Balázs plantea que el cine funciona, además de como instrumento artístico, como el más puro artificio de la técnica. Tomando como referencia al cine mudo de la época 4 , principalmente del imperante mercado occidental (Estados Unidos, Reino Unido y Francia), el teórico húngaro ofrece una perspectiva de comparación entre el aparato cinematográfico y la imprenta, marcándolos como los dos inventos técnicos que han transformado la vida del ser humano en comunidad a lo largo del devenir de las sociedades y las culturas.

\section{Al referirse a la imprenta, Balázs anuncia:}

Así, el espíritu visible se convirtió en espíritu legible y la cultura visual en conceptual. Es bien sabido que esa transformación cambió en general el aspecto de la vida. Pero se tiene menos en cuenta cómo pudo cambiar el rostro de propio ser humano: su frente, sus ojos, su boca (2013:41).

Según esta postura, las formas de comunicación visual quedaron extintas ante la llegada de la imprenta, y con ello se ha transformado también la vida en sociedad del ser humano. El espíritu visible de las sociedades, a través de diversas creaciones artísticas y eminentemente visuales como la pintura, la arquitectura o la escultura, quedó sometido al desarrollo de un nuevo invento, el libro, de espíritu legible, que modifica y trastoca las experiencias estético-artísticas. El individuo que todo lo ve pasará a convertirse en el individuo que todo lo empezará a leer, idealizando el acto de lectura por sobre el acto tradicional de la visión.

Lo que Balázs está planteando, por sobre todas las cosas, es la idea de que la literatura generada desde la imprenta establece nuevos parámetros de interpretación estética, a tal punto de socavar mutaciones en el régimen de la mirada, en términos cognitivos y psicológicos, de las sociedades. El lenguaje escrito superó al lenguaje visual, haciendo mella en las interrelaciones que el individuo construye y desarrolla con sus respectivos entornos.

Sin embargo, con la llegada del cinematógrafo en el siglo XIX, y su consolidación como medio de comunicación de masas durante las primeras décadas del siglo XX, el imperante estilo legible comienza a sufrir fisuras, ante la aparición del cine como instrumento exclusivamente visual. Como el propio Balázs expresa:

Ahora se trabaja con otra máquina que da a la cultura un nuevo giro hacia lo visual y un rostro nuevo al hombre. Se llama cinematógrafo. Igual que la imprenta, es una técnica de reproducción y difusión de producciones espirituales. Sus efectos sobre la cultura humana no serán menores (Balázs, 2013:41).

Igualando al cine con la tradición de la cultura escrita, el autor anticipa que el nuevo medio genera una revolución para la tradicional vida del ser humano. Esto coincide con el planteamiento de que con el nacimiento del cine, los regímenes del arte y de la imagen sufren una evolución, que dan como resultado nuevas formas de contemplación estética.

Es pertinente mencionar, trazando un eje histórico concep-

Recordemos que el advenimiento del cine sonoro sincronizado se concreta en el año 1927, con la película The Jazz Singer, dirigida por Alan Crosland. tual, la clasificación propuesta por Debray (1992:176), en la cual la imagen ha sufrido cambios desde sus distintas etapas de generación, circulación e interpretación simbólica. Por un lado, la etapa conocida como logosfera, se inicia con la creación de la escritura y lo visual hasta la invención de la imprenta. Es definida como era de los ídolos ${ }^{5}$, donde las creaciones visuales mantuvieron estrecha relación con las creaciones puramente escritas, en un sentido de contemplación, y hasta cierto punto, mágico. Una segunda etapa, denominada grafosfera, potencia la tradición escrita por sobre la visual, gracias a la llegada de la imprenta. Es definida como la era del arte, que eleva a las creaciones artísticas y literarias al estatuto de obras dignas de ser estudiadas por regímenes estéticos. Finalmente, con la llegada de los medios audiovisuales (el cine y la televisión), la grafosfera da lugar a la videosfera, una era eminentemente visual, en donde los nuevos medios, por medio de la técnica, establecen una cultura visual absoluta, y en cierto modo, radicalizada y revisionada de la primera era.

Balázs no es ajeno a esta clasificación, atendiendo a los parámetros del cine mudo en tanto se erige como nueva invención. Apelando a las categorías trazadas por Debray, la propuesta de Balázs establece una primera etapa, previa a la Imprenta, con lo visual como símbolo de lo mágico y lo religioso. Luego, durante la Imprenta, Balázs anuncia un viraje del sentido mágico de la imagen a lo estrictamente histórico y conceptual de lo literario, apelando a la racionalidad que emerge del libro escrito. Y, por último, con la llegada del cine, lo histórico-conceptual pasa a fundarse como algo técnico, de estimulante contenido visual, apelando a un mundo histórico plagado de producción y difusión de imágenes, con un cierto retorno a la condición mágica de la primera etapa, no tanto desde la condición del ídolo, sino desde la pura reproducción técnica.

En esta nueva era, Balázs manifiesta que la sociedad vuelve a ser visible por que el cine mudo no necesita de la palabra para funcionar como medio, sino que se vale de su medio más específico, la imagen en movimiento, para crear la posibilidad de un nuevo lenguaje, siempre en la estricta función de la técnica.

En la era en las que las primeras teorías fílmicas se preocuparon por la condición del cine como arte, Balázs expresa que el cine, para constituirse como medio artístico, debe instaurar una nueva forma de lenguaje, distinta a otras formas de arte, como la pintura, el teatro o la literatura, a las que siempre fue afín. Pero con una trascendente diferencia: el cine debe utilizar, para ello, el largamente olvidado lenguaje de las expresiones faciales y de los gestos, perdidos en la cultura legible, que proporcionarán una correspondencia visual del alma inmediatamente incorporada a la imagen (Balázs, 2013:42).

El teórico húngaro dice que el lenguaje de los gestos, las miradas y todo lo que circunda al mundo material, es la auténtica lengua materna de la humanidad (2013:42). Posteriores teóri$\cos ^{6}$, preocupados por la relación que existe entre las acciones humanas y las representaciones cinematográficas, indagarán sobre este asunto, pero el aporte pionero de Balázs resulta novedoso para el debate artístico de la época.

La creación de un lenguaje propio del cine, similar al de la realidad, proporciona para Balázs una nueva gramática, alejada

\footnotetext{
Del griego eidolon ( $\varepsilon(\delta \omega \lambda \mathrm{\jmath})$, que significa imagen.

6 Tal es el caso de Pier Paolo Pasolini, quien desde una postura afín al realismo, concibe al cine como el momento escrito de la realidad y una lengua escrita de la acción humana.
} 
de las convenciones simbólicas e interpretativas de la pintura, el teatro o la literatura. Esta gramática se basa en el accionar humano de la realidad, a través de los gestos y el movimiento, por lo que consideraba necesario la creación de un diccionario de gestualidades que definiera las correlaciones adecuadas entre la realidad circundante y la representación en pantalla. Esta propuesta recuerda la idea de lenguaje jeroglífico de Vachel Lindsay, quien promulgaba la creación de distintas imágenes que se corresponden recíprocamente con conceptos del mundo. Mientras que para Lindsay, el lenguaje del cine se basaría en las imágenes, para Balázs el lenguaje del cine serían las puras acciones humanas, ya presentes en nuestro mundo material. Incluso, la posición de Balázs sobre el cine va más allá: mientras que Lindsay cree que el lenguaje cinematográfico es fuente de especificidad como medio artístico, para Balázs es, además, su misión como arte que atiende a las masas. En este sentido, el cine genera una cultura visual que brinda nuevas formas de expresión a los seres humanos en su convivencia en sociedad.

El cine conforma, metafóricamente, una solución al problema de $\mathrm{Babel}^{7}$, con la creación del primer lenguaje internacional, en donde todas las naciones hablarán en base a una única raíz: la de las expresiones y los gestos (Balázs, 2013:42) Aquí, el cine se separará de otras artes de élite (tal y como pregonaba Canudo), para explorar sus propios recursos como arte esencial, debido a la paradójica doble cara del cine: como arte y como técnica, puesto que la reproductibilidad técnica de la obra artística tiende a modificar la relación de la masa con el arte (Benjamin, 1989:44).

Hasta aquí, un acercamiento a la misión del cine en relación a las masas, como aparato de comunicación, como medio artístico y como dispositivo técnico. La aparición cinematográfica ha generado mutaciones en las formas de comprensión del arte, desplazando límites de interpretación y potenciando la novedosa idea de la masividad técnica como fuente de contemplación estética.

Cuando Balázs propone que el cine debe tomar elementos de otras artes, también insinúa que debe tratar de buscar una forma propia de representación y de relación con la realidad, específica y autónoma, ajena de tradiciones convencionales, que explote su material técnico-artístico y consiga generar nuevos procedimientos de contemplación estética. De este modo, surge la interrogante sobre de qué materiales de expresión puede servirse el cine para la consolidación de su propio lenguaje.

\section{LA BÚSQUEDA Y CONSOLIDACIÓN DE UN LENGUAJE PROPIO}

Si bien asimila un discurso depuradamente formalista, Balázs dista de cualquier tipo de radicalismos. Para el autor, la materia prima del cine no es exactamente la realidad misma, sino el tema fílmico que se presenta ante la experiencia y se ofrece para ser transformado en cine (Andrew, 1993:121). Esta vertiente, aparentemente condecorativa a lo puramente formal, alude también a la presencia de la realidad en una situación previa al trabajo artístico. El cine, para el autor húngaro, no es únicamente el resultado del trabajo que realiza el artista respecto a sus materiales de producción, sino que es el proceso, el pasaje de la realidad material a la forma cinematográfica, lo que le otorga sentido al lenguaje fílmico.

Para Benjamin, el cine es el primer medio artístico que está en situación de mostrar cómo la materia colabora con el ser humano, convirtiéndose en un excelente instrumento de discurso materialista (1989:37). Esto significa que a la vez que se realiza el visionado de una obra fílmica, se explicita el trabajo realizado en la creación de dicha obra. Al mismo tiempo que se muestra el resultado (la película, con su determinado metraje, estética y contenido), se exhibe la tarea del realizador con la realidad bruta, y el trabajo que se propone desde la aplicación del lenguaje cinematográfico (puesta en escena, encuadres, montaje). Para el autor, es un trabajo indivisible y recíproco, que involucra tanto la estética de lo formal, como la creación de dicha estética.

Aludiendo a una postura empirista, Balázs anuncia que en primera instancia la condición artística del cine está dada por la experiencia que el realizador cinematográfico posee con la realidad. A esta idea inicial, que será retomada décadas más tarde por otros teóricos ${ }^{8}$, rápidamente Balázs le añade el ingrediente formal: el tema fílmico. El tema fílmico es el camino que la realidad, multifacética y presentada de diversas maneras para el ser humano, realiza al ser moldeada en imágenes. Es decir, el tema no es ni la realidad ni la obra, sino el proceso que se realiza desde la realidad a la obra en sí; es determinado tanto por el medio como por el material del que nace. Para que el tema fílmico sea visible debe nacer como resultado de la relación individuo-realidad, y además, digno de ser transformado en lenguaje cinematográfico.

Balázs se propuso estudiar las formas del cine examinando lo que él consideraba géneros marginales, ya que de esta manera podría ver las leyes y reglas de la forma cinematográfica (Andrew, 1993:127). En este punto toma al cine de vanguardia como polo de radicalización de la técnica formalista, y al cine documental como polo en donde se halla la presencia más realista del aspecto formal. Entremedio, el autor sitúa a los filmes de ficción, cuyo éxito en la utilización del lenguaje radicará en mantener un equilibrio entre la perspectiva del registro de realidad y el trabajo formal al que debe ser sometido.

Teniendo en cuenta su división entre géneros, los temas más adecuados para el lenguaje del cine son aquellos que se adaptan exclusivamente a su propio medio. Se plantea el hecho de que no es prudencial que grandes clásicos de la literatura tengan masivas adaptaciones al cine, puesto que la razón de su éxito radica en su ya eficaz adaptación al lenguaje literario. Incurrir en la traspolación de obras literarias de renombre a un

8 Tras la II Guerra Mundial, surge el paradigma de las teorías realistas, preocupadas por la relación que el cine tiene con la realidad, y de que se ven afectados los procesos fenomenológicos y ontológicos de la existencia. Destacan, en tre otras, las figuras de André Bazin, Siegfried Kracauer, Guido Aristarco o Cesare Zavattini, afiliados a dicha tradición de pensamiento. Véase Casetti (2005:22-23).
El mito de Babel hace referencia al pasaje bíblico que habla de de Babel, que pretendía llegar al cielo, y de la confusión de lenguas que Yahvé lanzó sobre sus constructores y trabajadores, tras ver el orgullo y la insolencia que dicho acto representaba. 
nuevo lenguaje implica asumir el riesgo de la carencia de especificidad del medio, provocando la clásica crítica de que la obra literaria termina siendo mejor que su adaptación cinematográfica. Por el contrario, Balázs está de acuerdo en adaptar obras literarias no reconocidas o que han tenido una baja aceptación entre los lectores, que al ser adaptadas al cine, son revisitadas de una forma totalmente novedosa y dinámica, gracias a la injerencia del lenguaje cinematográfico ${ }^{9}$.

Para la creación de este nuevo lenguaje, al que Balázs denominará "lenguaje-forma", se establece claramente que el cine debe diferenciarse de otras disciplinas ligadas a lo artístico, principalmente el teatro, algo que en sus inicios no estaba, en lo absoluto, consolidado:

Si el cine desde su infancia produjo nuevos temas específicos, nuevos personajes, un nuevo estilo, incluso una nueva forma de arte, ¿por qué entonces digo que aún no era un arte nuevo, sino simplemente una copia fotográfica de las representaciones teatrales? (Balázs, 1952:30).

A pocos años de su nacimiento, el cine era similar al teatro debido a que, técnica y estéticamente, cumplía sus tres principios formales principales: que el espectador ve la escena representada como un todo en el espacio, siempre desde una distancia fija inmutable, y cuyo ángulo de visión y perspectiva de las escenas nunca se modifica (Balázs, 1952:30). Esta etapa del cine, tradicionalmente llamada Modo de Representación Primitiva (Burch, 1995:193), reunía las tradicionales obras de los hermanos Lumière o las de Georges Méliès, cuya acción radicaba en vistas sin cambios en la escalaridad de planos, sin cortes espacio-temporales, y siempre con planos autárquicos, usualmente en valor general, y la cámara inmóvil, que exponían toda la acción en una sola toma. Además del teatro, el cine se emparentó en esta etapa de representación primitiva con recursos de la fotografía y la pintura.

Sin embargo, a fines del 1900 y durante la década del diez, los pertinentes trabajos de la Escuela de Brighton (que incluían entre sus realizadores a George Smith, Robert William Paul o James Williamson), el francés Ferdinand Zecca, y los norteamericanos Edwin S. Porter y, principalmente, David W. Griffith, posibilitaron la exploración de distintos recursos fílmicos, articulando una narrativa cinematográfica y posibilitando la creación de un Modo de Representación Institucional (Burch, 1995:193), alejado de lo primitivo. Balázs entiende que desde esta indagación surgió su lenguaje-forma, principalmente a través de tres recursos que consolidaron al cine como un lenguaje artístico propio e independiente de otras artes: el encuadre, el montaje y la escalaridad de planos, y de esto último, principalmente el primer plano (close-up) (1952:30).

En el capítulo "La función creadora de la cámara” de su Teoría del cine, Balázs expone que el encuadre y la angulación son los que dan forma a los objetos en pantalla. A diferencia del teatro, donde todos los objetos e intérpretes se visualizan en una distancia invariable y totalizadora, en el cine dos objetos, tomados desde distinta angulación y desde diversas formas de encuadre, son completamente distintos entre sí, dando lugar a distintos procesos de significación. Por ello, en el encuadre, Balázs encuentra un principio fundamental: el cine no reproduce las imágenes, sino que las produce genuinamente (1952:47).

9 Para Andrew, este podría ser el caso de obras como The Birth of a Nation, Touch of Evil, Psycho, The Searchers o The Treasure of the Sierra Madre (1993:122)
De esta manera, nos encontramos en la dicotomía producción/reproducción, donde el cine toma partido por extraer de la realidad aquellos elementos que mejor se adaptan a su lenguaje, para no únicamente realizar una función de registro, sino además, agregar nuevos significados desde el trabajo de la forma. El encuadre actúa como elemento catalizador de un espacio fílmico fragmentando (a diferencia del teatro o la pintura, que otorgan un aparente espacio material completo) y dándole distintos valores significativos dependiendo de la forma en la que es presentado en pantalla.

Gracias al encuadre, surge lo que Balázs denomina "la visión del operador", la manera en la que la cámara trabaja sobre la realidad, moldeando y transformándola, mientras le otorga nuevos sentidos que solamente se pueden hallar en la imagen cinematográfica. Es aquí en donde el cine expone de manera clara su función artística, puesto que apela a la creatividad de la cámara para encontrar nuevas formas sobre lo cotidiano, alejadas de una tradición realista, y preocupada por un trabajo tanto a nivel técnico como estético.

Dentro de las distintas posibilidades de encuadre, Balázs se va a centrar en una en particular: el primer plano (close-up), puesto que es un recurso que contempla las cosas ocultas, a la vez que devela sutil y delicadamente las cosas mínimas de la vida (1952:56). A la vez que se describe al primer plano como un trabajo formal, también es cargado de sobrenaturalidad: teniendo en cuenta que el cine es el lenguaje de los gestos y las emociones, el primer plano contribuirá de sobremanera a dicha máxima, puesto que evidenciará cada gesto y emoción del intérprete en pantalla, sin posibilidad de fingir su estado de ánimo, dada la cercanía espacial y emocional del encuadre.

El tratamiento del primer plano implica revelar la realidad de una manera más cercana e íntima, posibilitando la contemplación estética, acentuando la carga dramática y expresando la sensibilidad poética de la obra fílmica. Por otro lado, es un triunfo sobre el espacio fílmico, puesto que rompe con la autarquía teatral del espacio absoluto, y permite, en base a la escalaridad de planos, otorgar determinados significados según respectivos valores de encuadre.

Por último, al hablar de montaje, Balázs lo define como la asociación de todas las ideas visuales del filme, que otorga a cada toma su significado final (1952:119). De esta asociación, el espectador termina por deducir que ante la secuencia de imágenes que pasan ante sus ojos hay una predeterminación e interpretación intencional. Desde esta perspectiva, el montaje actúa en un doble territorio: por un lado selecciona, fragmenta y reúne los distintos planos, escenas y secuencias, para otorgar al filme una narrativa singular, pero por otro lado se convierte en un dispositivo marcadamente ideológico, puesto que si el espectador presupone la intencionalidad del mensaje fílmico, dicho mensaje no está exento de contenido teleológico, que encuentra en el montaje su articulador y vehículo principal.

La colección de imágenes que despliega el acto del montaje implica a su vez que el significado de dichas imágenes debe ser completado por el espectador, quien confirmará el sentido de la narrativa a través de la asociación de ideas y la imaginación (algo que estaba presente también en el proto-teórico Münsterberg). Posterior a esta explicación, Balázs explicita una categorización de los distintos tipos de montajes fílmicos, nombrando cuatro existentes: metafórico, poético, alegórico e intelectual (1952:126-128). 
Si bien cada categoría cumple una función dentro de los procesos narrativos de las obras fílmicas, es importante tener en cuenta que desde el montaje surgirán distintos recursos que potenciarán el lenguaje-forma del cine, el tránsito de la primitivización a lo institucional, junto a la exploración de la narrativa cinematográfica y, por ende, de su condición artística innata. Entre estos recursos, Balázs nombra a la asociación de ideas (relación entre uno o más planos de una secuencia), la continuidad de forma y atmósfera en la puesta en escena, y los procesos de analepsis y prolepsis narrativa, comúnmente llamados flashback y flashforward.

\section{ANOTACIONES FINALES}

La perspectiva de estudio de Béla Balázs resulta, a la vez de visionaria, pertinente para los debates de la época acerca de la artisticidad del cine. Ya desde su génesis, el fenómeno cinematográfico no estaba exento de ser tomado como objeto de ricos debates acerca de sus recursos como medio, su influencia sobre las sociedades y la relación que mantenía con otras disciplinas artísticas.

Balázs, desde una mirada formalista, entendió al cine como un arte que posee un elevado alcance con su público, volviéndolo parte de su operación sobre la realidad y transformando los regímenes de la cultura visual que imperaban previo al siglo $X X$. Con la llegada del aparato cinematográfico, el devenir del arte se ve trastocado por nuevas formas de ver, nuevos discursos basados en la técnica y la reproducción, que condicionan, sin lugar a dudas, el rol de las obras de arte en las sociedades y culturas occidentales.

Ante la perspectiva de Balázs, creímos conveniente repasar sus principales aportes a la teoría fílmica desde la condición del cine como medio artístico, para establecer un diálogo sobre el papel de la representación cinematográfica en el panorama cultural y estético de las sociedades. Se estableció un recorrido por tres vertientes principales de estudio, asumidas por Bálazs en su vasto trabajo. Por un lado, se observó la capacidad del cine para erigirse y consolidarse como un medio específicamente artístico; por otro lado, se intentó dilucidar la forma en la que el cine exploró los diversos recuersos del lenguaje fílmico; y por último se buscó evidenciar la importancia del aparato cinematográfico como un fenómeno comunicacional, con pertinencia simbólica y cultural, dentro de las sociedades del siglo XX.

Al respecto, resulta pertinente plantear que el pensamiento de Balázs posee una innegable vigencia. En la época actual, ante la multiplicidad de producción y consumo de medios de comunicación a nivel masivo, sumado a la convergencia de nuevos medios (digitales, principalmente), y su alcance a nivel global, es interesante observar como la mirada de Balázs es oportuna para establecer ricas líneas de debate. El teórico húngaro ya anunció, a principios de siglo XX, la influencia del cine como medio masivo, fenómeno que se repite en la actualidad con la proliferación de pantallas, principalmente de Internet, la televisión y los medios digitales.

La masificación de la cultura visual propuesta por Balázs a principios del siglo pasado, es la misma que se pone en debate en la actualidad en relación a las nuevas visualidades del ser humano y las nuevas dinámicas de comprender al mundo a través de los medios de comunicación. Por otra parte, la idea de que el cine generó nuevas formas de contemplación estética desde el momento de su creación se repite hoy en día con la influencia de lo digital en las nuevas dinámicas de representación, tanto a nivel fotográfico y cinematográfico, como en el ámbito de los fenómenos artísticos.

Tomando al autor según la tradición de su época, su pensamiento significa una perfecta síntesis de la teoría formalista y de las proto-teorías de principios de siglo. Su línea de investigación, afianzada a nivel estético, técnico y narrativo, devela una arista de opinión sobre el fenómeno cinematográfico de pertinencia absoluta, que precede a teorías posteriores y se enmarca dentro de postulados que, al día de hoy, resultan vigentes para cualquier discusión o debate acerca del nivel de artisticidad del cine y otros medios. 
Interrogarse sobre la veracidad del cine como arte, sobre si es una nueva forma de lenguaje o si es únicamente un mecanismo de reproducción no es algo, en lo absoluto, impermeable. Los estudios de la semiótica del cine de los años sesenta, la socio-semiótica de los años ochenta o las teorías cognitivas de mediados de los ochenta, confirman ese inmenso pensamiento interdisciplinar sobre el cine, desde las vertientes específicas de la práctica artística, pero también desde la rigurosa visión académica.

Desde estos puntos, volvemos a insistir en la figura de Béla Balázs como un precursor, un teórico del cine preocupado por el arte y la estética, por el advenimiento de la técnica y la respectiva respuesta de las sociedades, con la correspondiente responsabilidad del cine como medio de comunicación de masas. Su teoría fílmica resulta, a casi un siglo después de su aparición, un indicio para comenzar a preguntarse de qué manera el cine, con su lenguaje, su técnica y sus diversos recursos fílmicos, cada vez con más fuerza cultivó un camino propio rumbo a su deseada artisticidad. 
Andrew, D. (1993). Las principales teorías cinematográficas. Madrid: Rialp.

Balázs, B. (1952). Theory of the film. Londres. Editorial Dennis Dobson.

Balázs, B. (2013). El hombre invisible. La Torre del Virrey: revista de estudios culturales, (13), 41-44.

Benjamin, W. (1989). Discursos interrumpidos I. Buenos Aires: Taurus.

Burch, N. (1995). El tragaluz del infinito. Madrid: Cátedra.

Canudo, R. (1993). Manifiesto de las siete artes. En: Alsina Thevenet, H.; Romaguerá, J.; comp., Textos y manifiestos del cine. Madrid: Cátedra, 15-18.

Casetti, F. (2005). Teorías del cine. Madrid: Cátedra.

Debray, R. (1994). Vida y muerte de la imagen. Barcelona: Paidós.

Lindsay, V. (1916). The art of the moving picture. Nueva York: The MacMillan Company.

Münsterberg, H. (2005). El cine. Un estudio psicológico. Buenos Aires: Asociación Cultural Toscana de Buenos Aires.

Richter, H. (1951). The film as original art form. College Art Journal Vol. 10, No. 2. Recuperado de: https://www.jstor.org/stable/772314?seq=1\#page_scan_tab_contents

Stam, R. (2001). Teorías del cine: una introducción. Barcelona: Paidós. 